\title{
Foresight as a key enabler of innovation in the economy. Introduction to the topical collection
}

\author{
Anna Sacio-Szymańska ${ }^{1}$ - Gualtiero Fantoni ${ }^{2}$ • Cornelia Daheim ${ }^{3}$
}

Received: 21 November 2016 / Accepted: 21 November 2016/Published online: 3 December 2016

(C) The Author(s) 2016. This article is published with open access at Springerlink.com

\section{Background}

This Topical Collection strives to approach the role of Foresight as innovation enabler from two perspectives: that of business, and that of public research policy. Both points of view have received increasing attention in the literature, recently. For example in the special issues of Foresight or Technological Forecasting and Social Change on Strategic Foresight [1, 2], in the European Planning Studies journal or in books, such as What Works: Case Studies in the Practice of Foresight [3], Adaptive Governance for a Changing World [4] or The Evolution of Strategic Foresight: Navigating Public Policy Making [5]; to name just a few.

However, there are still white spaces that need to be brought into discussion. These include among others practical case studies and comparative analyses (with the specific focus on SMEs) on how Foresight actually impacts day-to-day decision-making and enables long-term innovation in companies. With regard to the impact of Foresight on innovation policies, undertaking studies of the connections between Foresight and innovation catalysing practices on national, European or beyond EU dimensions would certainly be worthwhile.

A well-defined context for the analysis of these topics of interests has been provided by the growing discussion and

Anna Sacio-Szymańska

anna.sacio@itee.radom.pl

1 Institute for Sustainable Technologies - National Research Institute, Radom, Poland

2 Department of Civil and Industrial Engineering, University of Pisa, Pisa, Italy

3 Future Impacts, Cologne, Germany interest in the launching of the next EU Framework Programme, as underlined by Robert-Jan Smits (DirectorGeneral DG RTD) ${ }^{1}$ :

"Foresight has been one of the three pillars of preparatory works in specifying the EU research agenda beyond 2020 (...) the agenda setting process needs to be topdown and bottom-up; so it could address the Grand Challenges properly".

During on-going debates many other relevant issues emerge, such as: the dilemma whether to support large companies with EU funds or whether to focus exclusively on SMEs. Both approaches have their pros and cons; such as: large enterprises can considerably supplement public funds with their own investments and focus on the frontier; longterm and risky research. Whereas directing public innovation measures towards SMEs could bring more immediate impact on the market and yield economic growth.

Another layer of the discussion is added once considering the uneven distribution of EU RTD funds across Europe. The lower success rate of project proposals from the newer member states - such as the EU-13 who joined the European Community in 2004, 2007 and 2013 - is easily evident.

This uneven participation by country in the Horizon 2020 is a challenge for the next EU framework programme ${ }^{2}$. However, equal distribution of funds for innovation among individual countries is not the solution that would secure the greatest economic benefits and sustainable development. In this context, it is understood that only the most innovative

\footnotetext{
${ }^{1}$ At stakeholders meeting "Research Strategies: Europe 2030 and the next Framework Programme" organised in Brussels in October 2016.

2 http://www.sciencebusiness.net/events/2016/research-strategies-europe2030-and-the-next-framework-programme. Accessed 18.11.2016
} 
business \& research actors would succeed in the competition for EU funding regardless of their country of origin.

Therefore, the final themes, which emerged from the above discussions, are:

- The need to integrate business, science, policy and citizens to tackle innovation challenges more effectively.

- The need to integrate Futures Studies with other disciplines to increase awareness; boost applications; and trigger novel methodological approaches.

- The need to integrate EU-15 with the EU-13.

For these reasons, the organizers of the 3rd Future Engineering 2016 conference $^{3}$ held in Starachowice, Poland in September 2016, broadened the scope of the event towards Foresight through the international Foresight Europe Network $(\mathrm{FEN})^{4}$ featured session on the interdependencies between Foresight and innovation management.

As the two previous editions show, the conference brings together science and business representatives ready to speak about commonly executed EU and privately-funded projects, to discuss encountered problems and win-win solutions in the wide theme of manufacturing technologies. This years' international FEN-featured Foresight session and panel discussion resulted in highlighting crucial needs and recommendations related to:

- Rebranding Foresight itself, underlining its practical value (especially to corporate beneficiaries and policy decision-makers) and benefits stemming from i.e. trend monitoring, roadmapping, future-oriented technology analysis, technology intelligence, innovation creation etc.

- Building Foresight excellence through the combination of evidence-based methods (quantitative) and societal needs-tailored approaches (qualitative) however always validated through consensus building (citizens' and, more in general, stakeholders' engagement).

- Increasing Foresight awareness; building capacity and demand among entrepreneurs and policy-makers through tailored formal and non-formal educational offers.

- Bringing together Futures Studies academic researchers and Foresight practitioners to allow for quality and applicability in Futures Research [6].

- Strengthening the role of Foresight as one of the key instruments in the implementation, monitoring and update of smart specialization strategies combined with Entrepreneurial Discovery Process.

- Paying attention to the risk of experts' biases or of assumptions being distorted by technology hypes, and the

\footnotetext{
${ }^{3}$ https://futureengineering.itee.radom.pl/index.php/2016-04-01-06-32-05 /about. Accessed 18.11.2016

${ }^{4}$ www.feneu.org
}

need for developing methods able to "see through" advertising, inflation, etc.

- Regarding Foresight activity as a nonlinear investigating process aimed at understanding weak signals or indicators able to trigger future developments or conversely to spot unknown issues able to prevent a technology to emerge. The capability to think in non-linear terms is something highly characterizing the Foresight domain nowadays.

During the conference, the general audience composed of engineers and entrepreneurs was introduced to 11 Foresight best practices presented by the representatives of Italy, Germany, Slovenia, Greece, Iran, Hungary, Austria, United Kingdom and Poland who answered to the call announced by conference organisers and FEN in co-operation with the European Journal of Futures Research (EJFR).

\section{Articles of the topical collection}

This Topical Collection contains some of the papers presented during the FEN 2016 conference Foresight session. Key topics, which were addressed by the authors, included the following:

- What is the interdependence between Foresight and the ability to create innovations in companies?

- How to increase Foresight awareness among companies?

- What factors affect Foresight ability in companies?

- How could qualitative Foresight information be (effectively) included in decision-making processes in companies? What are the main qualities of "good" future-oriented information?

- To what extent do companies rely on future-oriented information (i.e. trends, weak signals) in shaping their innovation strategies?

- How is Foresight process organized (aims, methods, results, results distribution, target groups, which internal departments or external actors are involved etc.)? What Foresight methods and tools are preferred in companies?

- What are key requirements for Foresight success and what are the reasons for Foresight failure in corporate environments?

- What are the differences in Corporate Foresight design and use among SMEs and large companies?

- How can regional authorities benefit from Foresight?

- What is the contribution of Foresight into smart specialization strategies and Entrepreneurial Discovery Process?

Out of the seven papers selected for publication in this Topical Collection, five contributions discuss the issue of business Foresight; whereas three papers propose 
methodological solutions and underline technology-related outcomes, developed and tested within Foresight projects commissioned by public entities. The papers are illustrated with the following case studies:

- SMEs based in Central and Eastern Europe (2 papers);

- A European Technology Platform (1 paper);

- A South-American civil, non-profit, private corporation (1 paper);

- A sectoral Foresight launched by a regional government in South-Europe (1 paper),

- A national Foresight exercise in a South-European country (1 paper) and

- A pan-European Foresight, which involves 30 countries (1 paper).

The papers cover a wide area of technologies, citizens and stakeholders and provide different time frames as well as time perspectives of both analysis and Foresight. The reader could find it of interest to discover short-term Foresight approaches in rapidly changing fields (e.g. biotechnologies and medical devices), medium term (Industry 4.0) and long term (when the change of an entire city is under study).

The paper of Björn Sautter aims to assess the ManuFuture Road towards EU Re-Industrialisation based on quality criteria for Futures Research in order to draw conclusions for effective Futuring activities in general and for the next ManuFuture strategy cycle. The article describes the need for strategic decision-making and constituency building in a complex and knowledge-driven socio-technologicaleconomic-political environment. To meet this need, the author introduces Futuring as a pragmatic way to explore future developments in order to make better, future-proofed, decisions and to strategically guide communities and organisations to jointly create a successful future (Cornish, 2004). The author proposes that the ecosystem approach has to be in the centre of an upcoming vision and constituency building process, integrating all relevant relations of the quintuple helix model, and broadening the scope with manufacturing as a key enabling function in a highly networked, digitizing and circular economy of the future.

Riccardo Apreda, Andrea Bonaccorsi, Felice dell'Orletta and Gualtiero Fantoni propose in their paper to apply a powerful methodological tool called Functional Analysis to the technology Foresight process. The paper describes this approach, which involves e.g. the analysis of patents and papers; it presents how to integrate it with text mining algorithms and experts' domain knowledge, and finally discusses its benefits in the context of technology Foresight also from an economic point of view. There are important benefits of the proposed methodology. For example: it contributes to overcoming cognitive biases and linear forecasting; it helps to detect weak signals, those even experts may not be aware of; it provides a way to see through technological hypes, promises and interests. In sum: it offers an effective way to cross-validate expertbased analyses (and vice versa). Another key benefit is that the proposed methodological tool makes Foresight affordable for actors who have limited resources for carrying out the expensive, complex, large, long and difficult to manage Foresight exercises, which are participation-oriented. Among the beneficiaries of the proposed methodological approach, the authors state: Small and Medium Enterprises, municipalities, hospitals or civic communities. A thorough theoretical analysis of this quantitative approach based on bibliometrics is illustrated with the case study from the medical device industry.

The paper of Emmanuel Koukios presents the surprising results of an experiment where an innovation explosion was catalysed by Foresight. In particular, the organizers of the endof-Greek-Foresight project conference proposed a competition among all conference participants with the theme: in how many ways can you peel an apple? More than 100 different solutions were recorded. In the paper, the role of Foresight in this phenomenon is analyzed with the help of transpersonal psychology findings, and its significance for the national innovation system is assessed.

In their paper, Niklas Gudowsky and Walter Peissl review the theoretical basis for transdisciplinary forward looking activities and provide first insights into an ongoing highly deliberative and reflexive Foresight and co-creation process engaging science, society and policy makers: CIMULACT - Citizen and Multi-Actor Consultation on Horizon2020. For the theoretical underpinnings of this paper, the authors draw on literature from the established inter-disciplines of futures studies, technology assessment (TA), and sustainability science as well as science and technology studies (STS). The empirical value of the paper lays in the presented and discussed intermediate results from the CIMULACT project. These include excerpts from Europe-wide citizens' visions and extracted explicit and implicit social needs towards Science, Technology and Innovation. The specific focus of the paper on the role of technology allows eliciting implications for governing sustainable human-centred technologies. The paper demonstrates that engaging citizens, stakeholders and experts in co-creating advice for research agendas serves for making science, technology and innovation more sustainable and responsive to societal needs.

The paper of Judit Gaspar argues that conscious future strategizing can be identified on the level of the everyday practices of strategy makers. The author argues that the Corporate Foresight activity is to be regarded not as a oneoff, periodic intervention, but as a process that is part of the operation of the organisation, through which the company looks for and finds its own way in the context of its everyday operation practice (Sarpong, Maclean, Alexander 2013). The processes concerned are characterised by specific levels of instinctive, reflexive or deliberate action, interpreted day by 
day in time, space and in the interpersonal relationships. The author aimed at understanding the analysed phenomenon of "constructing the future" in a more complex environment and capturing the factors that affect the phenomenon and their interrelationship. The paper aims to offer the possibility of mutual learning and fruitful dialog among practitioners and theorists as it provides both theoretical and practical implications that are derived from a case study that was conducted in a Hungarian SME (a children's book publishing company).

In their paper, Anna Sacio-Szymańska, Anna Kononiuk, Stefano Tommei, Ondrej Valenta, Eva Hideg, Judit Gaspar, Peter Markovič, Klaudia Gubova, Brigita Boorova discuss business futures of companies based in four representative countries of Central and Eastern Europe referred to as the Visegrad region. The authors discuss the results achieved so far in the project, which aims to help the companies from the region to advance their futures literacy and raise demand for business Foresight in the V4 region. The authors applied a combined macro- \& micro- scenario building approach, which provided an adequate way to make entrepreneurs familiar with both quantitative and qualitative Foresight methods. In the first stage (macro approach), the authors used and updated Atherton's (2005) scenarios based on datasets. The second stage (micro approach) involved a practical scenario workshop with a selected group of entrepreneurs representing the Visegrad region according to a more intuitive approach (described as four-quadrant scenarios), which resulted in individual company scenarios. The methodology described in the paper can be replicated by Foresight researchers and practitioners from other countries who wish to use Atherton's (2005) scenarios as a starting point when discussing the future of business in their countries. The authors claim that the method sufficiently met the goals of the project study: it revisited business scenarios for Visegrad region and it provided learning-by-doing Foresight experience to company representatives, who are thereby encouraged to experiment more with Foresight in their business practice.

The contribution by Abdul Yaver, Jenny Marcela SanchezTorres, Miguel Ángel Amórtegui and Lucas Giraldo Ríos J.M. Sánchez-Torres, M.A. Amórtegui, L. Giraldo-Ríos aims to identify and validate trends related to advanced technology services, and present strategic lines of action to the Colombian National Research and Education Network: RENATA $®$. The described case study is a civil, non-profit, private corporation responsible for the implementation and appropriation of new generation data network, providing services and facilitating the connection of Colombian institutes to the research and academic network of centres in the world. The described Foresight process had three stages: pre- foresight, Foresight and post-foresight. The methods applied included: country benchmarking, a survey, international expert consultations and structural analysis. The result of Foresight included: the list of necessary updates of the existing services offered by the network; the list of promising development directions along with detailed operational recommendations that will enable the introduction of new services by RENATA $₫$ in the future.

In summary, the papers of this Topical Collection analyze the role of Foresight in triggering changes in organisational, regional or national innovation eco-systems from various perspectives drawing on a rich and diverse needs towards Foresight in various communities from and beyond the EU. With the conference and the Topical Collection we aspire to "provide better understanding of how to use the future and how to enhance the integration of complexity into the decision-making" [7]. Thus, we aim to better embed Foresight researchers and practitioners into national, regional and local innovation ecosystems by strengthening their strategic support towards business, policy and RTD decision-making stakeholders.

Acknowledgements The guest-editors of this Topical Collection, the Foresight European Network leadership and the organisers of 2016 Future Engineering conference would like to express their gratitude to the EJFR scientific board and editorial team for this publishing opportunity.

Open Access This article is distributed under the terms of the Creative Commons Attribution 4.0 International License (http:// creativecommons.org/licenses/by/4.0/), which permits unrestricted use, distribution, and reproduction in any medium, provided you give appropriate credit to the original author(s) and the source, provide a link to the Creative Commons license, and indicate if changes were made.

\section{References}

1. Coates J, Durance P, Godet M (2010) Special issue strategic foresight. Technol Forecast Soc Chang J 77(9):1423-1610

2. Sarpong D, Amstéus MN, Amankwah-Amoah (2015) Special issue: strategic foresight. Foresight J 17(5):405-542

3. Inayatullah S (2015) What works: case studies in the practice of foresight. Metafuture, Tamkang

4. Wei Neng W (2016) Adaptive governance for a changing world. Civil Service College lectures

5. Kuosa T (2012) The evolution of strategic foresight: navigating public policy making. Routledge

6. Kuusi O, Cuhls K, Steinmüller K (2015) The futures map and its quality criteria. Eur J Futures Res 3(22). doi:10.1007/s40309-0150074-9

7. Miller R (2015) Learning, the future, and complexity: an essay on the emergence of futures literacy. Eur J Educ 50(4). DOI: 10.1111 /ejed.12157 